\title{
Pengaruh Budaya Terhadap Actual Use Digital Payment System Pada Pelaku UMKM di Kota Batam
}

\author{
Saut Pintubipar Saragih*, Nopriadi** \\ * Sistem Informasi, Universitas Putera Batam \\ ** Sistem Informasi, Universitas Putera Batam \\ pipin.sitio@gmail.com ${ }^{1}$, nopriadi.jamil@gmail.com ${ }^{2}$
}

\section{Article Info \\ Article history: \\ Received 2019-10-11 \\ Revised 2019-11-01 \\ Accepted 2019-11-18}

\section{Keyword:}

Actual use,

technology acceptance model, perceived of usefulness, perceived ease of use, $U M K M$

\begin{abstract}
Digital payment gateway yang digunakan masyarakat Kota Batam sangat beragam. Sistem pembayaran digital tersebut diantaranya adalah internet banking, mobile banking, mobile application payment, dan juga masih ada yang menggunakan electronic data capture. Jumlah pengguna yang paling banyak adalah penggun sistem pembayaran digital berbasis mobile banking dan internet banking yang mencapai hamper $80 \%$ dari total responden yang ada. Pelaku umkm di Kota Batam sudah mengenal sistem pembayaran digital dengan baik dan juga sudah menggunakan dalam rentang waktu yang cukup lama yaitu rata-rata tigas tahun. Budaya di Kota Batam ditinjau dalam hal teknologi informasi secara keseluruhan sudah baik dimana hasil olah data menunjukan bahwa $50 \%$ pelaku usaha sudah menerima sistem pembayaran digital untuk mendukung kegiatan usaha mereka. Hasil penelitian ini menyimpulka bahwa budaya memberikan pengaruh positif terhadap actual use (penggunaan) sistem pembayaran digital. Nilai signifikansi pada hasil pengolahan data kuesioner menunjukan bahwa variable budaya pelaku UMKM di Kota Batam tidak dominan terhadap variable actual use karena pada nilai $\mathrm{R}$ square pada table anova menghasilkan nilai 0,509 . Namun secara khusus pada uji regresi linier dan juga uji hipotesis menghasilkan kesimpulan bahwa budaya pelaku UMKM di Kota Batam mempengaruhi penggunaan sistem pembayaran digital.
\end{abstract}

Copyright (C) 2019 Journal of Applied Informatics and Computing. All rights reserved.

\section{Pendahuluan}

Pertumbuhan akses internet serta diikuti pengguna internet di Indonesia merupakan salah satu yang tercepat didunia. Saat ini data resmi menunjukkan bahwa pengguna internet aktif di indonesia adalah 143,26 juta pengguna dimana angka tersebut adalah $54,58 \%$ dari totap populasi penduduk Indonesia pada 2017 [1]. Secara khusus di Kota Batam hal ini juga terjadi yaitu antara lain dimanfaatkan oleh para pelaku usaha mikro kecil dan menengah (UMKM) sebagai alat-bantu untuk proses transaksi keuangan sederhana maupun rumit. Jumlah pelaku UMKM di Kota Batam saat secara resmi tercatat adalah 318 pelaku usaha [2]. Indonesia mengatur adanya kegiatan usaha Industri dimana terdapat jenis industri sedang (tenaga kerja 20-99 orang), Industri kecil (tenaga kerja 5-19 orang), Industri rumah tangga (tenaga kerja 1-4 orang), untuk UMKM diatur dalam Undang-Undang Nomor 20 Tahun 2008 dan Permendagri no 8 tahun 2014 tentang Usaha Mikro, ssaha kecil dan usaha menengah [3]. Pada periode pertumbuhan internet saat ini masyarakat Batam merupakan salah satu Kota yang sedang bertransisi dari Kota berkembang menjadi Kota maju sejak dilengkapinya infrastruktur teknologi. Pelaku usaha mikro kecil dan menengah di Kota Batam saat ini sudah banyak yang menggunakan sistem pembayaran digital namun belum digunakan oleh seluruh pelaku usaha UMKM.

Sistem pembayaran berbasis internet, mobile dan berbasis aplikasi yang disediakan oleh perusahaan pengembang software seperti gopay, ovo, serta aplikasi lainnya sudah masuk pasar Kota Batam. Namun budaya masyarakat secara keseluruhan belum mendukung penggunaan siste pembayaran digital tersebut dilakukan secara penuh di Kota Batam. Masyarakat Kota Batam masih banyak menggunakan penggunaan uang tunai untuk kegiatan transaksi dibanding dengan menggunakan pembayaran berbasis digital payment gateway (gerbang pembayaran digital). Di beberapa daerah atau negara lain siste pembayaran digital diketahui dapat menguntungkan usaha atau bisnis yang mereka jalankan karena adanya efisiensi dan efektifitas proses bisnis yang disukai oleh konsumen. Di Indonesia pembayaran digital 
mulai disukai oleh masyarakat terutama masyarakat milenial [4].

Sistem pembayaran yang digunakan oleh masyarakat juga ikut berevolusi seiring dengan teknologi yang berkembang tersebut [5] seperti penggunaan mobile banking dan mobile payment. Digital payment adalah cara pembayaran berbasis non-cash (non tunai) yang menggunakan uang digital [6]. Saat ini di Indonesia uang digital paling banyak market share yang paling banyak digunakan adalah dari gopay [7].

Penelitian terkait acceptance sistem informasi banyak menggunakan model TAM (Technology acceptance model) [8], banyak berubah dari awal muncul pada tahun 1985 oleh Fred Davis dan pertama sekali digunakan pada tahun 1986.

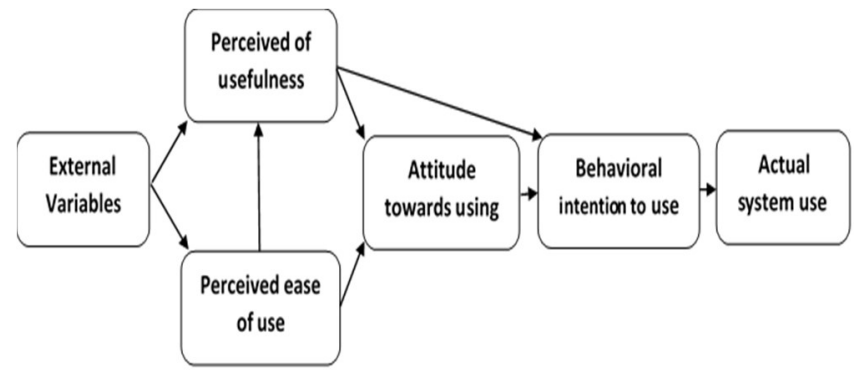

Gambar 1. Model technology acceptance model

Pada model TAM terdapat external variable pada penelitian ini dipilih peubah yaitu budaya. Budaya pada pengguna sistem informasi yang sudah melekat pada diri pengguna tersebut dapat digunakan sebagai variable yang mempengaruhi penerimaan suatu teknologi kepada user yang menggunakannya [9]. Budaya tersebut dapat mencakup latar belakang Pendidikan, lingkungan di lokasi user tersebut menggunakan sistem yang mereka gunakan, jangakauan koneksi internet, dukungan dari pemerintah dan kebijakan lainnya, serta perangkat infrstruktur lain yang tersedia.

\section{METODOLOGI PENELITIAN}

\section{A. Lokasi Penelitian, Populasi dan Sample}

Lokasi penelitian yang ditetapkan pada penelitian ini yaiti diutamakan di Kota Batam saja dengan cakupan kecamatan Batu Aji sebaga daerah yang diambil sebagai wilayah yang paling utama. Populasi pelaku usaha mikro kecil dan menengah (UMKM) di Kota Batam adalah 318 pengusaha yang secara resmi didata oleh Dinas terkait di Kota Batam. Peneliti menggunakan jumlah pelaku tersebut sebagai acuan populasi untuk menentukan besarnya sample yang akan diteliti. Pada penelitian [10], rumus dalam menghitung sampel pada populasi dengan metode sederhana dari slovin adalah sebagai berikut.

$n=\frac{N}{1+N e^{2}}$

Maka peneliti meyakini dengan tingkat kepercayaan sebesar $95 \%$ dan margin of error dalam penelitian ini adalah $5 \%$ atau
0,05 dan total sample sehingga sample adalah 178 orang pelaku umkm di Kota Batam.

\section{B. Analisis Data}

Untuk melakukan analisis data pada penelitian ini menggunakan analisis data deskriptif dan analisis kuantitatif dengan menggunakan metode regresi linear sederhana. Analisis deskriptif digunakan untuk menjelaskan secara deskripsi terkait hasil temuan pada data yang telah diolah oleh peneliti. Metode regresi linear sederhana digunakan untuk menguji hipotesis penelitian yaitu emnguji pengaruh variable bebas (budaya) terhadap variable terikat (actual use) yang ada. Untuk melakukan proses pengolahan data digunakan alat-bantu perangkat lunak statistic yakni SPSS.

\section{Model Penelitian}

Model penelitian yang dirancang adalah berdasarkan dari hasil rancangan pemikiran dan teori yang ada serta artikel yang telah diteliti sebelumnya.

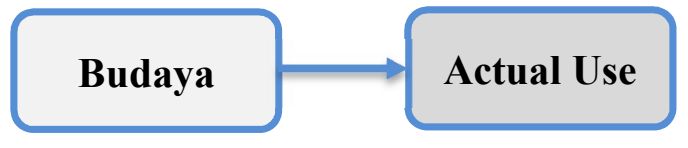

Gambar 2. Hipotesis penelitian

Untuk mengumpulkan data dari seluruh responden maka digunakan item pertanyaan penelitian berikut ini:

Variable Budaya (Culture $(\mathrm{Cu})$ ):

- Cu1: Di Lingkungan atau Lokasi anda bisa mendapatkan akses Internet yang stabil dan konsisten

- $\mathrm{Cu}$ 2: Anda berpengalaman dan mengerti dalam menggunakan komputer serta aplikasi inovatif dan kreatif berbasis mobile dan internet

- Anda mengerti dan mampu mempelajari aplikasi pembayaran atau keuangan yang inovatif dan kreatif yang tersedia secara offline ataupun secara online Variable Actual Use (AU):

- Sistem pembayaran digital saya gunakan sebab memberikan kelebihan dan keuntungan

- Menerapkan atau menggunakan sistem pembayaran digital pada proses kerja lain pada usaha.

- Pencatatan keuangan dapat dipermudah oleh sistem pembayaran digital.

\section{Hyphothesis Penelitian}

Model TAM yang dijadikan acuan pada penelitan ini tidak akan dijadikan seluruhnya sebagai variable operasional yang akan diukur. Berdasarkan penelitian yang pernah dilakukan oleh peneliti sebelumnya bahwa banyak faktor yang bisa menyebabkan sebuah sistem diterima atau ditolak [9]. Faktor tersebut oleh pengguna dijadikan external variable pada penelitian ini, maka penulis memutuskan untuk mengambil external variable pada model TAM untuk diuji langsung pengaruhnya terhadap actual use digital payment system oleh pelaku UMKM di Kota Batam. 
Berikut merupakan hipotesis penelitian yang ditetapkan pada penelitian ini:

- Ho: budaya mempengaruhi actual use digital payment system oleh pelaku UMKM di Kota Batam

- Ha: budaya tidak mempengaruhi actual use digital payment system oleh pelaku UMKM di Kota Batam

\section{Pembahasan}

\section{A. Profil Responden}

Jumlah sample pada penelitian yang telah ditetapkan adalah sebanyak 178 orang pelaku UMKM. Namun kuesioner penelitian yang diisi oleh responden yang dinyatakan valid dan bisa digunakan sebagai data penelitian adalah sebanyak 165 responde. Profil atau demografi responden yang diambil adalah alamat, jenis usaha, jenis sistem pembayaran digital yang digunakan dan lama penggunaan daripada sistem yang mereka gunakan tersebut.

Jenis usaha yang terdapat pada profil penelitian sangat beragam. Beberapa contoh dari jenis usaha tersebut adalah catering, penyedia alat, penjual souvenir, penjual stationary, percetakan, dan digital printing dan yang lain-lain yang termasuk dalam usaha UMKM. Pada gambar dibawah dapat dilihat proil dari responden yang telah ikut serta dalam penelitian ini.

\section{Jenis Produk Digital Payment yang Digunakan Dan Atau Pernah Digunakan} 165 responses

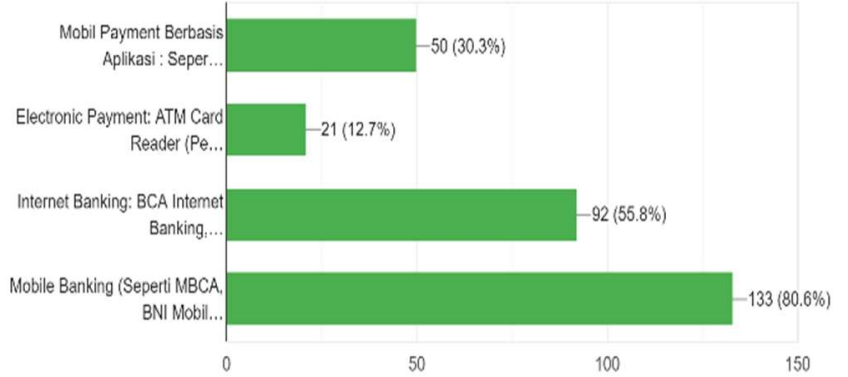

Gambar 3. Sistem pembayaran digital yang dipakai pelaku UMKM

Pada gambar 3 dapat dilihat bahwa hampir semua jenis gerbang pembayaran yang ada sudah pernah digunakan oleh pelaku usaha di Kota Batam. Jenis pembayaran yang digunakan adalah sebagai berikut:

- Mobile payment (seperti ovo, gopay, dan lain-lain)

- Electronic payment (atm card reader/edm)

- Internet banking (bca internet bankin, mandiri internet banking, dan lain-lain)

- Mobile banking (seperti mbca, bni mobile, btn mobile, mandiri mobile dan lain-lain).

Melihat data yang ada dapat disimpulkan bahwa gateway yang paling banyak digunakan adalah sistem pembayaran melalui mobile banking yakni mencapai $81 \%$ dari total responden yang menjawab [11], diikuti internet banking 55\%, mobile payment sebanyak $30 \%$ dan hanya $12 \%$ yang menggunakan alat elektronik sepeti electronic data capture (EDC) yang biasanya dikeluarkan oleh pihak bank terkait.

\section{Berapa Lama Menggunakan Layanan Digital Payment.}

\section{5 responses}
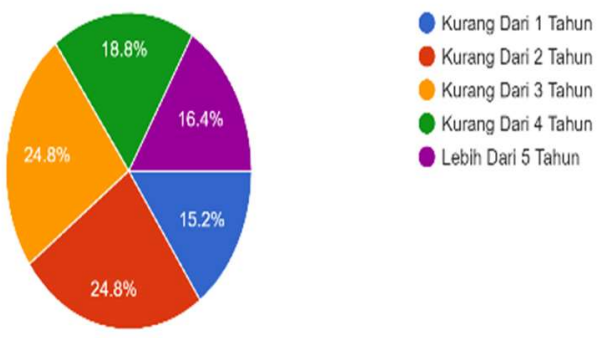

Gambar 4. Lama Penggunaan digital payment oleh pelaku UMKM

Berdasarkan data yang dikumpulkan maka dapat dilihat bahwa internet sudah sangat dikenal di Kota Batam sejak 5 tahun terakhir. Hal ini secara sederhana dapat terbukti dari data yang didapatkan bahwa hampir seluruh pelaku usaha sudah pernah menggunakan digital payment sistem. Lama penggunaan yang paling banyak adalah 0 tahun sampai 3 tahun sebesar 24,8\%, kurang dari 1 tahun sebanyak $15 \%$, kurang dari 4 tahun sebesar $18 \%$.

\section{B. Pembahasan}

Data yang telah dikumpulkan dapat dilihat hasil olah data menggunakan statistik pada tabel berikut.

\section{1) Rata-rata isian kuesioner penelitian}

Pada tabel dibawah dapat dilihat data isian kuesioner yang dilakukan oleh responden

TABEL I

FREKUENSI ISIAN KUESIONER PENELITIAN

\begin{tabular}{|l|r|r|}
\hline \multicolumn{1}{|c|}{ Variable } & \multicolumn{1}{c|}{ N } & \multicolumn{1}{c|}{ Mean } \\
\hline $\mathrm{Cu} 1$ & 165 & 3.89 \\
\hline $\mathrm{Cu} 2$ & 165 & 3.77 \\
\hline $\mathrm{Cu} 3$ & 165 & 3.82 \\
\hline $\mathrm{AU} 1$ & 165 & 4.09 \\
\hline $\mathrm{AU} 2$ & 165 & 3.96 \\
\hline $\mathrm{AU} 3$ & 165 & 4.03 \\
\hline $\begin{array}{l}\text { Valid N } \\
\text { (listwise) }\end{array}$ & 165 & \\
\hline
\end{tabular}

Pada tabel I dapat dilihat bahwa seluruh item pertanyaan dijawab oleh sebanyak 165 orang pelaku usaha UMKM di Kota Batam. Rata-rata item pertanyaan terjawab adalah valid tanpa ada yang kosong atau hilang.

2) Uji Normaitas Data Kuesioner

Pengujian Regresi sederhana harus didahului dengan pengujian distribusi data yang normal atau tidak normal. 
Berikut merupakan hasil pengujian normalitas data dengan menggunakan metode uji Kolmogorov-Smirnov Test. Pada tabel tersebut didapatkan bahwa nilai sig adalah $>0,05$ yaitu 0,064 sehingga nilai data dianggap terdistribusi dengan normali.

TABEL II

ONE-SAMPLE KOLMOGOROV-SMIRNOV TEST

\begin{tabular}{|l|l|r|}
\hline \multicolumn{2}{|c|}{} & \multicolumn{1}{|c|}{$\begin{array}{c}\text { Unstandardized } \\
\text { Residual }\end{array}$} \\
\hline $\mathbf{N}$ & Mean & $\mathbf{1 6 5}$ \\
\hline \multirow{2}{*}{$\begin{array}{l}\text { Normal } \\
\text { Parameters }\end{array}$} & Std. Deviation & $0 \mathrm{E}-7$ \\
\hline \multirow{3}{*}{$\begin{array}{l}\text { Most Extreme } \\
\text { Differences }\end{array}$} & Absolute & .33392969 \\
\cline { 2 - 3 } & Positive & .102 \\
\cline { 2 - 3 } & Negative & .059 \\
\hline Kolmogorov-Smirnov Z & .102 \\
\hline Asymp. Sig. (2-tailed) & 1.311 \\
\hline \multicolumn{2}{|l|}{ a. Test distribution is Normal. } \\
\hline \multicolumn{2}{|l|}{ b. Calculated from data. } \\
\hline
\end{tabular}

\section{3) Uji Linearitas Data Kuesioner}

Syarat selanjutnya yang harus dipenuhi oleh sebuah pengujian regresi adalah penguji linearitas yan ditujukan untuk menguji apakah masing-masing variable memiliki tingkat linearitas yang baik. Berikut merupakan hasil uji linearitas yang didapatkan yaitu nilai siginifikansi pada tabel anova sebesar 0,45 yang mana angka tersebut menyatakan bahwa masing-masing memiliki nilai linearitas yang valid untuk diuji regresi.

TABEL III

UJI LINEARITAS VARIABLE

\begin{tabular}{|c|c|c|c|}
\hline & & & Sig. \\
\hline \multirow{5}{*}{$\begin{array}{l}\text { Culture * } \\
\text { Actual_Use }\end{array}$} & \multirow{3}{*}{$\begin{array}{l}\text { Between } \\
\text { Groups }\end{array}$} & (Combined) & .000 \\
\hline & & Linearity & .000 \\
\hline & & $\begin{array}{l}\text { Deviation from } \\
\text { Linearity }\end{array}$ & .045 \\
\hline & \multicolumn{2}{|c|}{ Within Groups } & \\
\hline & \multicolumn{2}{|l|}{ Total } & \\
\hline
\end{tabular}

\section{4) Uji Regresi Sederhana}

Uji regresi dilakukan untuk mendapatkan persamaan regresi yang dibutuhkan untuk ujia hipotesis dan pengambilan kesimpulan penelitian. Persamaan regresi sederhana adalah Y $=\mathrm{a}+\mathrm{bX}$.

Maka persamaan regresi sederhana yang dapat diambil dari hasil uji regresi dari tabel coefficient adalah sebagai berikut.

- $\mathrm{a}=1,771$
- $\mathrm{b}=0.804$

- $\mathrm{Y}=1,771+0.804 \mathrm{X}$

TABEL IV

UJI REGRESI SEDERHANA

\begin{tabular}{|c|c|c|c|c|c|c|}
\hline \multicolumn{7}{|c|}{ Coefficients $^{\mathrm{a}}$} \\
\hline \multirow{2}{*}{\multicolumn{2}{|c|}{ Model }} & \multicolumn{2}{|c|}{$\begin{array}{c}\text { Unstandardized } \\
\text { Coefficients }\end{array}$} & \multirow{2}{*}{$\begin{array}{c}\text { Standardized } \\
\text { Coefficients } \\
\text { Beta }\end{array}$} & \multirow[t]{2}{*}{$\mathbf{t}$} & \multirow[t]{2}{*}{ Sig. } \\
\hline & & B & $\begin{array}{l}\text { Std. } \\
\text { Error }\end{array}$ & & & \\
\hline \multirow{2}{*}{1} & (Constant) & 1.771 & .757 & & 2.339 & .021 \\
\hline & Actual_Use & .804 & .062 & .713 & 12.991 & .000 \\
\hline
\end{tabular}

\section{5) Uji Hipotesis}

Setelah melakukan uji regresi dengan didahului oleh pengujian normalitas dan linearitas maka akan dilakukan uji hipotesis. Sebelumnya hipotesis pada penelitian ini adalah sebagai berikut.

- Ho: budaya mempengaruhi actual use digital payment system oleh pelaku UMKM di Kota Batam

- Ha: budaya tidak mempengaruhi actual use digital payment system oleh pelaku UMKM di Kota Batam

Maka hasil uji hipotesis dengan menggunakan tabel koefisien seperti pada tabel IV adalah yang pertama dengan melihat nilai sig pada tabel koefisien. Nilai koefisien adalah 0,000 dimana artinya nilai tersebut lebih kecil dari nilai 0,05 yang merupakan nilai probabilitas yang sudah ditetapkan. Maka dengan demikian keputusan hipotesis nya adalah sebagai berikut:

- Ho diterima

- Ha ditolak

\section{6) Hasil Penelitian:}

Seluruh tahapan pengolahan data telah selesai dilaksanakan dan hasil penelitian ini adalah mendapatkan bahwa budaya memberikan pengaruh signifikan terhadap penerimaan teknologi pembayararn digital pada pelaku umkm di Kota Batam. Melalui uji distribusi data didapatkan bahwa data responden yang diambil sudah normal dan variable budaya memiliki linearitas yang baik dengan variable actual use sistem digital payment.

Pada tabel anova terdapat juga nilai $\mathrm{R}$ square yakni 0,509. Angka ini menunjukan bahwa hanya 50,9\% variable actual use sistem digital payment dipengaruhi oleh variable culture, sedangkan sisanya adalah dipengaruhi oleh variabel lainnya. 
Hal ini sejalan dengan beberapa penelitian sebelumnya bahwa masih banyak faktor lain yang mempengaruhi user untuk dapat menerima atau menggunakan sebuah sistem [9][12][13]. Pada penelitian [9] menghasilkan penelitian bahwa terdapat variable budaya, keamanan, dan performance dan penelitian [13] menggunakan external variable seperti umur, jenis kelamin dan budaya sehingga ada banya faktor yang diteliti yang menimbulkan banyak korelasi pada setiap variable, sedangkan penelitian ini hanya fokus pada variable eksternal budaya yang diasumsikan mempengaruhi penerimaan sistem informasi oleh user. Pada penelitian [12] hanya fokus pada satu jenis digital payment sedangkan penelitian ini mencakup seluruh jenis digital payment yang digunakan oleh seluruh pelaku UMKM di Kota Batam.

\section{KESIMPULAN}

Budaya (Culture) merupakan sebuah hal yang tidak dilepaskan dari masyarakat. Culture terbentuk dari banyak faktor yang memungkinkan hal tersebut menjadi sebuah ciri atau karakter yang dimiliki dan dapat digunakan sbagai factor keuntungan dalam suatu hal. Culture dalam penelitian ini belumlah mewakilki seluruh variable yang bisa menjawab hipotesis lain sehingga perlu dibuktikan kembali dengan menggunakan variable tambahan untuk mendapatkan hasil yang lebih baik. Namun menyumbang 50\% dari variable yang mempengaruhi actual use pembayaran digital.

Actual use pada sistem pembayaran digital di Kota Batam diketahui telah digunakan hamper oleh seluruh pelaku Kota Batam. Melalui profil data penelitian bahwa rata-rata pengusaha umkm di Kota Batam telah menggunakan sistem pembayaran digital sejak 5 tahun terakhir dimana gerbang pembayaran yang paling banyak digunakan adalah pembayaran berbasis mobile dan internet banking. Hal ini memang sejalan dengan begitu pesatnya pertumbuhan penjualan mobile devices di dunia atau khususnya juga di Kota Batam. Pada penelitian ini juga disimpulkan bahwa budaya mempengaruhi pelaku usaha umkm untuk menggunakan sistem pembayaran digital.

\section{UCAPAN TERIMA KASIH}

Terima kasih diucapkan oleh peneliti kepada Kementerian Kementerian Riset, Teknologi, dan Pendidikan Tinggi Republik Indonesia yang telah memberikan dukungan dalam proses penyelesaian penelitian ini.

\section{DAfTAR Pustaka}

[1] APJII, "Penetrasi \& Perilaku Pengguna Internet Indonesia 2017," Asos. Penyelenggara Jasa Internet Indones., pp. 1-39, 2017.

[2] V. S. E Janrosl, D. E. Sari, and S. T. Tuwonaung, "Pembinaan Financial Report pada Pelaku UMKM Kecamatan Sagulung Batam," Jppm J. Pengabdi. Dan Pemberdaya. Masy., vol. 1, no. 2, p. 139, 2017.

[3] UU No. 20 Tahun 2008, "Peraturan Menteri," UU No. 20 Tahun 2008, no. 1, pp. 1-31, 2008.

[4] Databoks, "Transaksi Perbankan Berbasis Digital Terus Meningkat," 2017.

[5] A. Demirguc-Kunt, L. Klapper, D. Singer, S. Ansar, and J. Hess, The Global Findex Database 2017: Measuring Financial Inclusion and the Fintech Revolution. 2018.

[6] R. USMAN, "Karakteristik Uang Elektronik Dalam Sistem Pembayaran," Yuridika, vol. 32, no. 1, p. 134, 2017.

[7] G. Company, "Easier payment with gopay," 2018 . .

[8] D. E. Kurniawan, A. Saputra, P. Prasetyawan, and others, 'Perancangan Sistem Terintegrasi pada Aplikasi Siklus Akuntansi dengan Evaluasi Technology Acceptance Model (TAM)', J. RESTI (Rekayasa Sist. dan Teknol. Informasi), vol. 2, no. 1, pp. 315-321, 2018.

[9] Junadi and Sfenrianto, "A Model of Factors Influencing Consumer's Intention to Use E-payment System in Indonesia," Procedia Comput. Sci., vol. 59, no. Iccsci, pp. 214-220, 2015.

[10] Riduwan and Akdon, Rumus dan Data dalam Aplikasi Statistika, Alfabeta, 2013.

[11] M. J. Alsamydai, "Adaptation of the Technology Acceptance Model (TAM) to the Use of Mobile Banking Services," no. 2014, pp. 2016-2028, 2016.

[12] M. Mbogo, "The Impact of Mobile Payments on the Success and Growth of Micro-Business: The Case of M-Pesa in Kenya," $J$. Lang. Technol. Entrep. Africa, vol. 2, no. 1, pp. 182-203, 2010.

[13] K. Suma Vally and K. Hema Divya, "A Study on Digital Payments in India with Perspective of Consumer"s Adoption," Int. J. Pure Appl. Math., vol. 119, no. 15, pp. 1259-1267, 2018. 